\title{
Hubungan Pengetahuan Kesehatan Gigi dan Mulut Dengan Status Kebersihan Gigi dan Mulut pada Penyandang Tunanetra Dewasa
}

\author{
Noviana F. Tandra \\ Christy N. Mintjelungan \\ Kustina Zuliari
}

\author{
Program Studi Pendidikan Dokter Gigi Fakultas Kedokteran \\ Universitas Sam Ratulangi Manado \\ Email: noviana.tandra11@gmail.com
}

\begin{abstract}
Limitations in vision of people with visual impairment affect their ability to gain knowledge, including oral and dental knowledge. Therefore, they are not able to keep their oral and dental health properly. This study was aimed to determine the correlation between oral and dental health knowledge and oral hygiene status among adult people with blindness. This was a descriptive analytical study with a cross sectional design. Data were obtained by using questionnaire and examination of oral hygiene status using the oral hygiene indexsimplified (OHI-S). Data were analyzed by using the Pearson correlation test. Subjects were 35 adult people with blindness aged 18-45 years. The results showed that 24 subjects $(68.57 \%)$ had poor level of knowledge and 11 subjects $(31.43 \%)$ had good level of knowledge. There were 10 subjects $(28.57 \%)$ with poor oral hygiene status, 24 subjects $(68,57 \%)$ with moderate oral hygiene status, and 1 subjects $(2.86 \%)$ with good oral hygiene status. The Pearson correlation test showed a $P$ value of 0.009 . Conclusion: There was a significant correlation between oral and dental health knowledge and oral hygiene status among adult people with blindness.
\end{abstract}

Keywords: oral and dental health knowledge, oral hygiene status, blindness

\begin{abstract}
Abstrak: Keterbatasan dalam penglihatan yang dimiliki oleh penyandang tunanetra memengaruhi kemampuan mereka dalam memperoleh pengetahuan, tepenyandangrmasuk pengetahuan kesehatan gigi dan mulut. Hal ini mengakibatkan penyandang tunanetra kurang optimal menjaga kebersihan gigi dan mulut. Penelitian ini bertujuan untuk mengetahui hubungan pengetahuan kesehatan gigi dan mulut dengan status kebersihan gigi dan mulut pada penyandang tunanetra usia dewasa. Jenis penelitian ialah deskriptif analitik dengan dessain potong lintang. Data penelitian diperoleh dengan menggunakan kuisioner serta pemeriksaan status kebersihan gigi dan mulut menggunakan oral hygiene index-simplified (OHI-S). Subyek penelitian berjumlah 35 penyandang tunanetra berusia 18-45 tahun diperoleh dengan menggunakan teknik total sampling. Data dianalisis dengan menggunakan uji korelasi Pearson. Hasil penelitian mendapatkan dari 35 subyek, terdapat 24 penyandang $(68,57 \%)$ dengan tingkat pengetahuan rendah, 11 penyandang $(31,43 \%)$ dengan tingkat pengetahuan tinggi. Terdapat 10 penyandang $(28,57 \%)$ dengan status kebersihan gigi dan mulut buruk, 24 penyandang $(68,57 \%)$ dengan status kebersihan sedang, dan 1 penyandang $(2,86 \%)$ dengan status kebersihan gigi dan mulut baik. Uji korelasi Pearson mendapatkan nilai $P=0,009$. Simpulan: Terdapat hubungan bermakna antara pengetahuan kesehatan gigi dan mulut dengan status kebersihan gigi dan mulut pada penyandang tunanetra dewasa.

Kata kunci: pengetahuan kesehatan gigi dan mulut, status kebersihan gigi dan mulut, tunanetra
\end{abstract}


Masalah kesehatan gigi dan mulut pada masyarakat salah satunya timbul karena faktor perilaku atau sikap mengabaikan kebersihan gigi dan mulut. Di Indonesia masalah kesehatan gigi dan mulut tergolong tinggi, berdasarkan data dari Riset Kesehatan Dasar (RISKESDAS) 2013 bahwa sebesar 25,9\% penduduk Indonesia mempunyai masalah kesehatan gigi dan mulut. Provinsi Sulawesi Utara merupakan salah satu dari enam provinsi yang memiliki nilai tertinggi dalam masalah kesehatan gigi dan mulut dengan prevalensi sebesar 31,6\%. ${ }^{1}$

Pengetahuan merupakan faktor yang membentuk perilaku seseorang. Semakin banyak pancaindera yang dilibatkan dalam menerima sesuatu, semakin kompleks pengetahuan yang didapat. Dalam proses belajar daya serap indera penglihatan yang paling tinggi sehingga penglihatan merupakan indera paling penting dalam menerima pengetahuan. $^{2}$

Masalah gigi dan mulut bisa terjadi karena kurangnya menjaga kebersihan gigi dan mulut misalnya karies atau lubang pada gigi yang bisa mengenai siapa saja tanpa mengenal usia. ${ }^{3}$ Penilaian kebersihan rongga mulut dalam suatu komunitas dapat diukur menggunakan oral hygiene indexsimplified (OHI-S) yang merupakan gabungan dari penilaian debris index simplified (DI-S) dan calculus index simplified (CI-S). ${ }^{4}$

Keterbatasan indera penglihatan menyebabkan munculnya hambatan dalam praktik kebersihan gigi dan mulut (oral hygiene). Penyandang tunanetra berisiko mempunyai status kesehatan gigi dan mulut yang lebih buruk dibandingkan dengan orang yang memiliki penglihatan normal. ${ }^{5}$ Keterbatasan menjadi salah satu hambatan penyandang tunanetra untuk memperoleh pengetahuan tentang kesehatan gigi dan mulut yang nantinya akan menentukan sikap dan tindakan dalam menjaga kebersihan gigi dan mulut. ${ }^{2}$

Usia juga memengaruhi pengetahuan kesehatan gigi dan mulut. Berdasarkan hasil Rapat Kamar Perdata dan Pasal 47 dan Pasal 50 Undang-Undang No 1 Tahun
1974 dinyatakan bahwa batas usia dewasa dan cakap hukum ialah yang telah mencapai umur 18 tahun atau sudah kawin. ${ }^{6}$

Penelitian ini bertujuan untuk mengetahui hubungan tingkat pengetahuan kesehatan gigi dan mulut dengan status kebersihan gigi dan mulut pada penyandang tunanetra usia 18-45 tahun.

\section{METODE PENELITIAN}

Jenis penelitian yang dilakukan ialah deskriptif analitik dengan desain potong lintang. Penelitian ini dilaksanakan di Panti Sosial Bina Netra (PSBN) Tumou Tou Manado di Paal IV.

Subyek penelitian ialah 35 orang penyandang tunanetra di PSBN Tumou Tou Manado usia dewasa yang diperoleh dengan metode total sampling berdasarkan kriteria inklusi dan eksklusi Pengetahuan kesehatan gigi dan mulut adalah pengetahuan tentang cara menjaga kebersihan gigi dan mulut yang dinilai berdasarkan kuisioner yang diisi pada saat penelitian, sedangkan status kebersihan gigi dan mulut adalah keadaan kebersihan gigi dan mulut yang diukur dengan menggunakan OHI-S dari Greene dan Vermillion dengan cara menjumlahkan skor indeks debris dan skor indeks kalkulus.

Informed consent dibacakan untuk dimintakan persetujuan, kemudian subyek penelitian diwawancara secara langsung untuk menjawab pertanyaan dalam kuisioner, dan dilakukan pemeriksaan kebersihan gigi dan mulut yang diukur dengan OHI-S.

Data yang diperoleh diolah dengan menggunakan program SPSS dan disajikan dalam bentuk tabel distribusi frekuensi.

\section{HASIL PENELITIAN \\ Karakteristik subyek}

Berdasarkan jenis kelamin dari 35 subyek terdapat 27 orang $(77,14 \%)$ berjenis kelamin laki-laki dan 8 orang $(25,86 \%)$ berjenis kelamin perempuan. Berdasarkan usia didapatkan 15 orang $(42,86 \%)$ berusia 18 -25 tahun, 12 orang $(34,28 \%)$ berusia $26-$ 35 tahun, dan 8 orang $(22,86 \%)$ berusia $36-$ 45 tahun. 
Pengetahuan kesehatan gigi dan mulut dan status kebersihan gigi dan mulut

Distribusi hasil penilaian tingkat pengetahuan kesehatan gigi dan mulut dan hasil pemeriksaan status kebersihan gigi dan mulut dapat dilihat pada Tabel 1 dan 2. Sebagian besar subyek penelitian memiliki tingkat pengetahuan rendah $(68,57 \%)$ dan status kebersihan gigi dan mulut sedang $(68,57 \%)$

Data hasil pemeriksaan tingkat pengetahuan kesehatan gigi dan mulut dan status kebersihan gigi dan mulut diuji menggunakan uji normalitas Kolmogorov-Smirnov untuk melihat distribusi masing-masing variabel. Hubungan antara variabel bebas dan variabel terikat diuji dengan uji korelasi Pearson. Hubungan pengetahuan kesehatan gigi dan mulut dengan status kebersihan gigi dan mulut pada penyandang tunanetra dewasa di PSBN Timou
Tou Manado dapat dilihat pada Tabel 3.

Tabel 1. Distribusi tingkat pengetahuan subyek penelitian

\begin{tabular}{ccc}
\hline Pengetahuan & $\begin{array}{c}\text { Jumlah } \\
(\mathbf{n})\end{array}$ & $\begin{array}{c}\text { Persentase } \\
(\mathbf{\%})\end{array}$ \\
\hline Tinggi & 11 & 31,43 \\
Rendah & 24 & 68,57 \\
Total & 35 & 100 \\
\hline
\end{tabular}

Tabel 2. Distribusi status kebersihan gigi dan mulut

\begin{tabular}{ccc}
\hline $\begin{array}{c}\text { Status } \\
\text { kebersihan } \\
\text { gigi dan mulut }\end{array}$ & $\begin{array}{c}\text { Jumlah } \\
(\mathbf{n})\end{array}$ & $\begin{array}{c}\text { Persentase } \\
(\boldsymbol{\%})\end{array}$ \\
\hline Baik & 1 & 2,86 \\
Sedang & 24 & 68,57 \\
Buruk & 10 & 28,57 \\
Total & 35 & 100 \\
\hline
\end{tabular}

Tabel 3. Hubungan tingkat pengetahuan kesehatan gigi dan mulut dengan status kebersihan gigi dan mulut responden

\begin{tabular}{|c|c|c|c|c|c|c|c|c|}
\hline \multirow{3}{*}{$\begin{array}{c}\text { Tingkat } \\
\text { pengetahuan }\end{array}$} & \multicolumn{6}{|c|}{ Status kebersihan gigi dan mulut } & \multicolumn{2}{|c|}{ Total } \\
\hline & \multicolumn{2}{|c|}{ Baik } & \multicolumn{2}{|c|}{ Sedang } & \multicolumn{2}{|c|}{ Buruk } & \multirow[t]{2}{*}{$\mathrm{n}$} & \multirow[t]{2}{*}{$\%$} \\
\hline & $\mathrm{n}$ & $\%$ & $\mathrm{n}$ & $\%$ & $\mathrm{n}$ & $\%$ & & \\
\hline Tinggi & 1 & 2,86 & 10 & 28,57 & 0 & 0 & 11 & 31,43 \\
\hline Rendah & 0 & 0 & 14 & 40 & 10 & 28,57 & 24 & 68,57 \\
\hline Total & 1 & 2,86 & 24 & 68,57 & 10 & 28,57 & 35 & 100 \\
\hline
\end{tabular}

Pada uji normalitas KolmogorovSmirnov didapatkan nilai $P=0,2(P>0,05)$ maka dapat disimpulkan bahwa data berdistribusi normal. Untuk mengetahui hubungan pengetahuan kesehatan gigi dan mulut dengan status kebersihan gigi dan mulut dipakai uji korelasi sederhana Pearson, dan diperoleh nilai signifikansi $P$ $=0,009 \quad(P<0,05)$ yang menunjukkan terdapat hubungan bermakna antara tingkat pengetahuan kesehatan gigi dan mulut dengan status kebersihan gigi dan mulut pada penyandang tunanetra dewasa.

\section{BAHASAN}

Hasil penelitian menunjukkan bahwa secara keseluruhan dari 35 subyek pene- litian sebagian besar berjenis kelamin lakilaki $(77,14 \%)$. Hal ini sejalan dengan penelitian yang dilakukan oleh John et al. ${ }^{7}$ mengenai pengetahuan dan praktik kesehatan gigi dan mulut serta prevalensi status karies pada penyandang tunanetra di Chennai. Hal ini berbeda dengan data yang didapatkan dari Riskesdas tahun 2013 bahwa jenis kecacatan tertinggi yaitu tunanetra dengan prevalensi penyandang disabilitas pada perempuan lebih tinggi dibandingkan laki-laki. ${ }^{1}$ Hal ini mungkin disebabkan karena tempat penelitian ini merupakan sarana untuk melatih ketrampilan termasuk memijat dan laki-laki menunjukkan jumlah minat yang lebih besar menjadi tukang pijat. ${ }^{8}$ 
Berdasarkan usia subyek penelitian, sebagian besar berada pada kelompok usia $18-25$ tahun $(42,86 \%)$ dan yang paling sedikit pada usia $36-45$ tahun $(22,86 \%)$.

Hasil penelitian tentang pengetahuan kesehatan gigi dan mulut mendapatkan 11 orang $(31,43 \%)$ dengan tingkat pengetahuan tinggi sedangkan yang dengan tingkat pengetahuan rendah sebanyak 24 orang $(68,57 \%)$. Hal ini sejalan dengan penelitian yang dilakukan Chang dan Shih $^{9}$ mengenai pengetahuan kesehatan gigi dan mulut dan praktik kebersihan mulut pada siswa tunanetra dan siswa normal di Taiwan yang menyatakan bahwa penyandang tunanetra memiliki pengetahuan kesehatan gigi dan mulut yang masih kurang. Hal ini dikarenakan kehilangan atau berkurangnya fungsi indera penglihatan sehingga edukasi tentang cara menjaga kesehatan gigi dan mulut juga kurang. ${ }^{10}$ Indera penglihatan memegang peranan yang penting dalam proses pembentukkan pengertian atau konsep sehingga adanya keterbatasan daya tangkap visual maka tidak bisa memperoleh pemahaman yang diberikan secara utuh. ${ }^{11}$

Data hasil pemeriksaan status kebersihan gigi dan mulut yang diukur dengan menggunakan OHI-S menunjukkan bahwa hampir seluruh subyek penelitian memiliki status kebersihan gigi dan mulut sedang, namun terdapat 1 orang $(2,86 \%)$ yang memiliki status kebersihan gigi dan mulut baik dan 10 orang $(28,57 \%)$ memiliki staus kebersihan gigi dan mulut buruk. Hal ini selaras dengan penelitian yang dilakukan oleh Sami et al. ${ }^{12}$ yang menyatakan status kebersihan gigi dan mulut yang buruk pada kelompok tunanetra. Hal ini disebabkan karena keterbatasan penglihatan yang mengakibatkan tunanetra menjadi sulit menilai apakah cara membersihkan gigi dan mulut yang sudah dilakukan sudah tepat atau tidak. ${ }^{13}$

Hasil penelitian menunjukkan persentase tertinggi yaitu yang mempunyai tingkat pengetahuan rendah dengan status kebersihan gigi dan mulut sedang berjumlah 14 penyandang (40\%). Dalam penel-tian ini juga terdapat 10 penyandang $(28,57 \%)$ yang memiliki tingkat pengeta- huan rendah dan status kebersihan gigi dan mulut buruk. Uji korelasi Pearson menunjukkan adanya hubungan bermakna antara tingkat pengetahuan kesehatan gigi dan mulut dengan status kebersihan gigi dan mulut pada tunanetra usia dewasa dengan $P=0,009$.

Pengetahuan tentang menjaga kesehatan gigi dan mulut yang kurang mengakibatkan kesulitan dan keterbatasan dalam menjaga kesehatan gigi dan mulut sehingga akibatnya penyandang tunanetra memiliki resiko status kebersihan gigi dan mulut yang buruk yang juga akan berpengaruh pada risiko karies yang tinggi dibandingkan dengan kelompok yang bukan tunanetra. ${ }^{14}$ Pengetahuan yang baik tentang kesehatan gigi dan mulut akan berpengaruh positif terhadap sikap dan tindakan dalam menjaga kesehatan gigi dan mulut. Mengetahui prosedur pembersihan gigi dan mulut yang benar merupakan dasar untuk menjaga kebersihan gigi dan mulut yang baik. ${ }^{15}$

Pada penelitian ini didapatkan bahwa tingkat pengetahuan yang rendah memiliki status kebersihan dan mulut yang buruk $(28,57 \%)$, sedangkan tingkat pengetahuan kesehatan gigi dan mulut yang tinggi tidak memiliki status kebersihan gigi yang buruk. Hal ini sejalan dengan penelitian yang dilakukan oleh Sari et al. ${ }^{16}$ yang menyatkan bahwa pengetahuan kesehatan gigi dan mulut yang baik akan memengaruhi status kebersihan gigi dan mulut menjadi baik. Hal ini disebabkan karena pengetahuan merupakan dasar terbentuknya suatu perilaku. Jika tingkatan pengetahuan lebih tinggi, perhatian kesehatan gigi akan tinggi begitu juga sebaliknya jika pengetahuan kurang perhatian perawatan gigi juga rendah.

Berdasarkan hasil penelitian ini didapatkan bahwa sebgaian besar penyandang tunanetra di PSBN Manado memiliki tingkat pengetahuan rendah dengan nilai rerata 14,97, dan nilai rerata untuk status kebersihan gigi dan mulut yaitu 4,36 yang berarti buruk. Hal ini menyimpulkan bahwa sebagian besar subyek penelitian memiliki tingkat pengetahuan yang rendah serta status kebersihan gigi dan mulut yang 
buruk. Hal ini mungkin disebebkan oleh keterbatasan yang mereka miliki sehingga memberi batasan untuk memperoleh pengetahuan secara utuh dan tidak mempunyai kemampuan untuk menjaga kebersihan gigi dan mulut.

\section{SIMPULAN}

Berdasarkan hasil penelitian ini dapat disimpulkan bahwa terdapat hubungan bermakna antara pengetahuan tentang kesehatan gigi dan mulut dengan status kebersihan gigi dan mulut pada penyandang tunanetra dewasa.

\section{SARAN}

Disarankan kepada Kepala Dinas Kesehatan dan Puskesmas Kota Manado untuk lebih meningkatkan kegiatan penyuluhan serta pemeriksaan gigi dan mulut secara rutin kepada penyandang tunanetra.

Bagi klinisi diharapkan dapat melakukan penyuluhan dan sosialisasi tentang kesehatan gigi dan mulut dengan cara dan komunikasi yang efektif pada penyandang tunanetra dewasa.

Untuk penelitian selanjutnya, diharapkan dapat melakukan penelitian lanjut dengan cakupan yang beragam sehingga hasilnya dapat digunakan secara umum untuk pengembangan kesehatan gigi dan mulut.

\section{DAFTAR PUSTAKA}

1. Riskesdas. Riset Kesehatan Dasar. Badan Penelitian dan Pengembangan Kesehatan Republik Indonesia. Jakarta: Laporan Nasioanal, 2013.

2. Maribun EB, Mintjelungan CN, Pangemanan DHC. Hubungan tingkat pengetahuan tentang kesehatan gigi dan mulut dengan status karies gigi pada penyandang tunanetra. eG. 2016;4(2): 177-82.

3. Indahwati V, Mantik MFJ, Gunawan PN. Perbandingan status kebersihan gigi dan mulut pada anak berkebutuhan khusus pada anak SLB-B dan SLB-C Kota Tomohon. eG. 2015;3(2):361-6.

4. Anggraini CW, Melok AW, Peni $P$. Gambaran status kebersihan rongga mulut dan status gingiva pasien RSGM
Universitas Jember Oktober-November tahun 2015. Pustaka Kesehatan. 2016; 4(2):365-74.

5. Mir'atannisa IM. Resiliensi mahasiswa tunanetra (Studi kasus terhadap mahasiswa tunanetra tidak dari lahir di Fakultas Ilmu Pendidikan Universitas Negeri Yogyakarta). Jurnal Bimbingan dan Konseling. 2017;3(6):309-25.

6. Dharma ADS. Keberagaman pengaturan batas usia dewasa seseorang untuk melakukan perbuatan hukum dalam peraturan perundang-undangan di Indonesia. Jurnal Repertorium. 2015; 2(2):168-76.

7. John JR, Daniel B, Paneerselvam D, Rajendran G. Prevalence of dental caries, oral hygiene knowledge, status, and practices among visually impaired individuals in Chennai, Tamil Nadu. International Journal of Dentistry. 2017: p.1-6. Article ID 9419648. Available from: https://doi.org/ 10.1155/2017/9419648

8. Noor A. Pemberdayaan ekonomi tunanetra komunitas sahabat mata Desa Jatisari Kecamatan Mijeng Semarang. Jurnal Pemikiran Agama untuk Pemberdayaan. 2014;14(1): h.1-16.

9. Chang CHS, Shih YH. Knowledge of dental health and oral hygiene practices of Taiwanese visually impaired and sighted student. JVIB. 2005;98(5).

10. Sabilillah MF, Kristiani A. Hubungan oral hygiene dengan keterampilan menggosok gigi pada anak tunanetra. ARSA. 2017;2(2):23-8.

11. Heriyanto $Y$, Niken $W$, Bambang $P$. Hubungan antara pengetahuan, persepsi dan sikap terhadap kesehatan gigi pada siswa tunanetra di Panti Sosial Bina Netra (PSBN) Wyata Guna Bandung. Sains kesehatan. 2005;18(2):237-50.

12. Ahmad MS, Jindal MK, Saif K, Hashmi SH. Oral health knowledge, practice, oral hygiene status and dental caries prevalence among visually impaired students in residential institutie of Aligarh. Journal of Dentistry and Oral Hygiene. 2009;1(2):023-6.

13. Girsang E. Perbandingan oral hygiene dan karies pada anak tunanetra dan tidak tunanetra pada usia 12 dan 15 tahun. Medan: FKG USU; 2003.

14. Al-qahtani Z, Wyne AH. Caries experience 
Tandra, Mintjelungan, Zuliari: Hubungan pengetahuan kesehatan gigi dan ...

and oral hygiene status of blind, deaf and mentally retarded female children in Riyadh, Saudi Arabia. Tropical Dental Journal. 2004;27(105):37-40.

15. Prashant ST, Das UM, Gopu H. Oral helath knowledge, practice, oral hygiene status, and dental caries prevalence among visually impaired children in
Bangalore. Journal of Indian Society of Periodontics and Preventive Dentistry. 2011;29(2):102-5.

16. Sari DS, Yuliana MDA, Tantin E. Hubungan pengetahuan kesehatan gigi mulut dengan status kebersihan rongga mulut pada lansia. IKESMA. 2014;11(1):44-5. 